\title{
Self-propagating high temperature synthesis and magnetic properties of $\mathrm{Ni}_{0.35} \mathrm{Zn}_{0.65} \mathrm{Fe}_{2} \mathrm{O}_{4}$ powders
}

\author{
YAO LI*, JIUPENG ZHAO ${ }^{\dagger}$ and JIECAI HAN \\ Centre for Composite Materials, ${ }^{\dagger}$ Department of Applied Chemistry, Harbin Institute of Technology, \\ Harbin 150001, People's Republic of China
}

MS received 9 January 2002; revised 6 June 2002

\begin{abstract}
Ni-Zn ferrite powders were synthesized by self-propagating high temperature synthesis (SHS) method. X-ray diffraction, TEM and vibrating sample magnetometry (VSM) were used to characterize the phase composition, microstructure and magnetic properties of the combustion products. The effect of the combustion temperature $\left(T_{\mathrm{c}}\right)$, the major parameter of the SHS process, on particle size, phase composition and magnetic properties of the products was also studied. The results showed that particle size grew with the increasing combustion temperature. The maximum saturation magnetization, $M_{\mathrm{s}}$, increased with combustion temperature indicating the growth of grain size and high degree of ferritization, while residual magnetization, $M_{r}$, and coercive force, $H_{c}$, decreased. Compared with other methods, $\mathrm{Ni}_{0.35} \mathrm{Zn}_{0.65} \mathrm{Fe}_{2} \mathrm{O}_{4}$ ferrite powders with improved magnetic properties can be obtained by $\mathrm{SHS}$ at $1000^{\circ} \mathrm{C}$.
\end{abstract}

Keywords. SHS; Ni-Zn ferrite powders; combustion temperature; particle size; magnetic properties; phase composition.

\section{Introduction}

Nickel-zinc ferrites are considered as one of the most versatile soft ferrites because of their high resistivity and low eddy current losses (Taylor et al 1995; Stoppels 1996). Ni-Zn ferrites have been commercially used in radio frequency circuits, high-quality filters, rod antennas and transformer cores.

In recent years, self-propagating high-temperature synthesis of ferrites attracted the interest of many researchers (Komarov et al 1993; Avakyan et al 1994; Bowen and Derby 1997). Compared with the conventional ceramic process, SHS method has some advantages, such as high productivity, low external energy consumption, short synthesis time, simple facility and high quality of the products. Although there have been many attempts to obtain various ferrites through SHS methods, no systematic study about the effect of the combustion temperature on microstructure and magnetic properties of $\mathrm{Ni}-\mathrm{Zn}$ ferrite powders was reported in the literature. In this paper, we report on the SHS process, the characterization and the magnetic properties of $\mathrm{Ni}-\mathrm{Zn}$ ferrite powders. In addition, we also investigated the effect of the combustion temperature on particle size, phase composition and magnetic properties of combustion products.

*Author for correspondence

\section{Experimental}

\subsection{Materials}

The raw materials used in preparation of $\mathrm{Ni}_{0.35} \mathrm{Zn}_{0.65}$ $\mathrm{Fe}_{2} \mathrm{O}_{4}$ are iron, iron oxide, nickel oxide and zinc oxide. The purity of the raw materials is more than $99 \%$. Table 1 shows the average particle size and purity of the raw materials.

\subsection{Procedure and property measurements}

The starting materials were weighed according to the required stoichiometric proportion, mixed and pressed into $20 \sim 40 \mathrm{~mm}$ thick pellets (diameter $12 \sim 15 \mathrm{~mm}$ ) and then were put into a quartz container. The experiments were carried out in a water-cooled tube. A schematic diagram of high pressure SHS chamber is shown in figure 1. A tungsten wire was used to initiate the SHS reaction. The combustion reaction which utilized the heat released from iron oxidation reaction was self-sustained

Table 1. Average particle size and purity of raw materials.

\begin{tabular}{llrrr}
\hline Substances & $\mathrm{Fe}$ & $\mathrm{Fe}_{2} \mathrm{O}_{3}$ & $\mathrm{NiO}$ & $\mathrm{ZnO}$ \\
\hline Average size $(\mu \mathrm{m})$ & 20 & 0.8 & 0.5 & 0.5 \\
Purity $(\%)$ & 99.0 & 99.0 & 99.5 & 99.5 \\
\hline
\end{tabular}


until the reactants were completely converted to the products. The loose green body was then milled and $\mathrm{Ni}-$ $\mathrm{Zn}$ ferrite powders were obtained. The flow chart of SHS process is shown in figure 2.

The major parameter of the SHS process, combustion temperature $\left(T_{\mathrm{c}}\right)$, was measured with $\mathrm{Pt} / \mathrm{Rh}$ thermocouples pressed into the mixture and registered by a recorder.

X-ray diffraction analysis (XRD) was used to investigate the phase composition and the ferritization degree of the products. The magnetic characterization of the products was conducted on an vibrating sample magnetometer (VSM, M-9500, USA). A laser diffraction analyser was used to measure the average grain size of the raw material and the products. The size and shapes of the particles were analysed by transmission electron microscopy (TEM, Philips CM12/STEM, Holland).

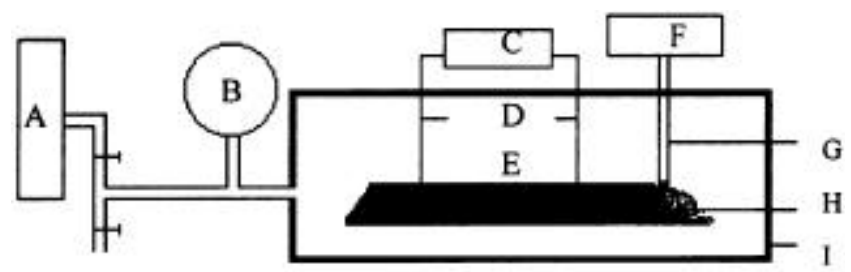

Figure 1. Schematic diagram of high pressure SHS chamber (A. oxygen, B. oxygen pressure meter, C. recorder, D. thermocouples, E. the reactants, F. ignitor, G. tungsten wire, H. ignition agent, I. SHS chamber).

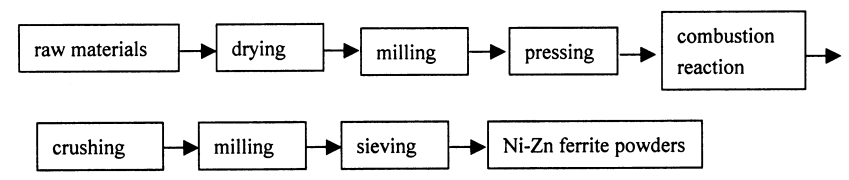

Figure 2. The flow chart of SHS process.

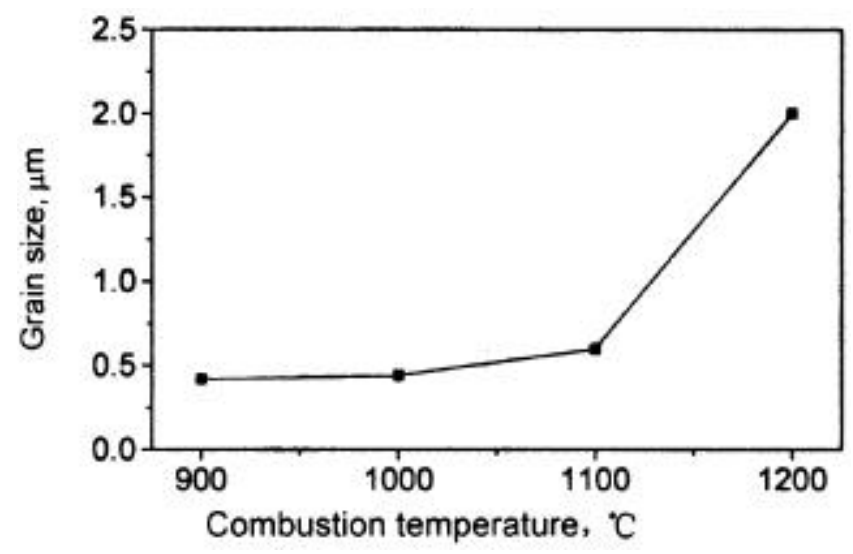

Figure 3. The relationship between grain size of $\mathrm{Ni}-\mathrm{Zn}$ ferrite powders and combustion temperature.

\section{Results and discussion}

Figure 3 shows the effect of combustion temperature on particle size of $\mathrm{Ni}-\mathrm{Zn}$ ferrite powders. As the figure illustrates, the particle size grows with the increasing com-

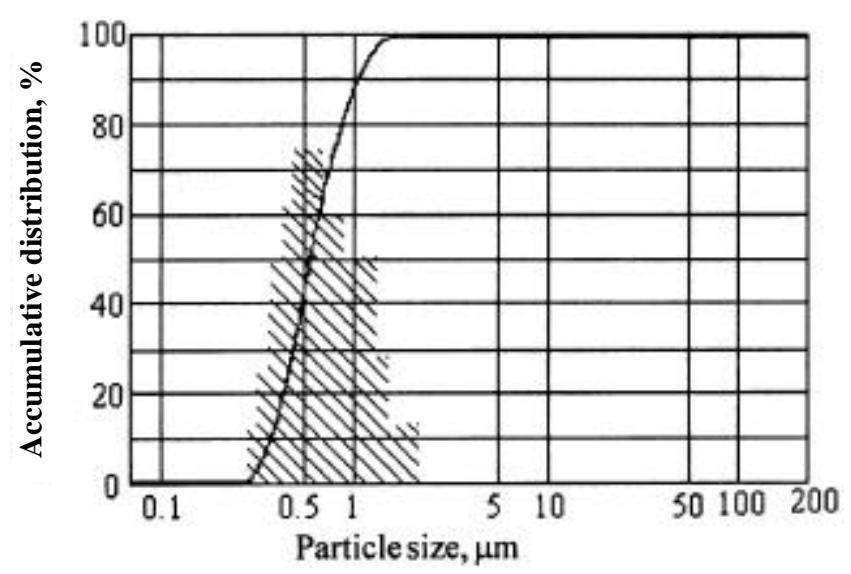

Figure 4. Size distribution of $\mathrm{Ni}-\mathrm{Zn}$ ferrite powders obtained at $1000^{\circ} \mathrm{C}$.

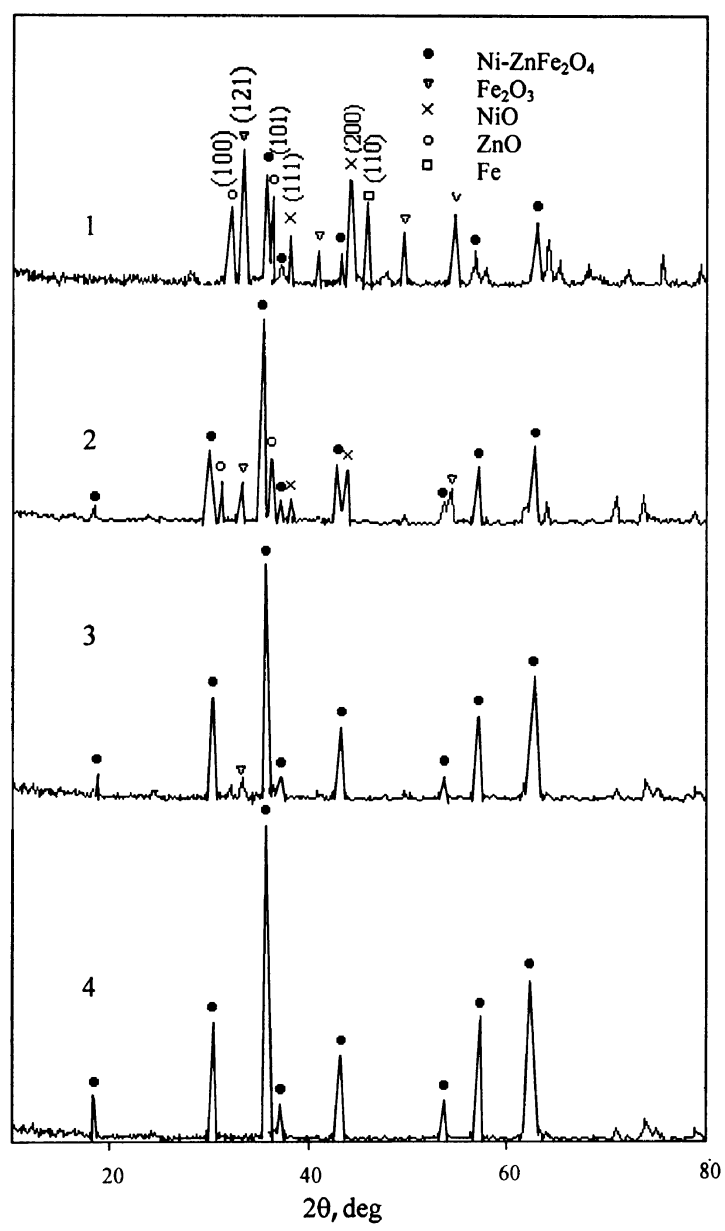

Figure 5. The XRD results of the products at different combustion temperatures $\left(1.700^{\circ} \mathrm{C} ; 2.900^{\circ} \mathrm{C} ; 3.1000^{\circ} \mathrm{C} ; 4.1200^{\circ} \mathrm{C}\right)$. 
bustion temperature. When combustion temperature is above $1100^{\circ} \mathrm{C}$, the particle grain size will grow substantially.

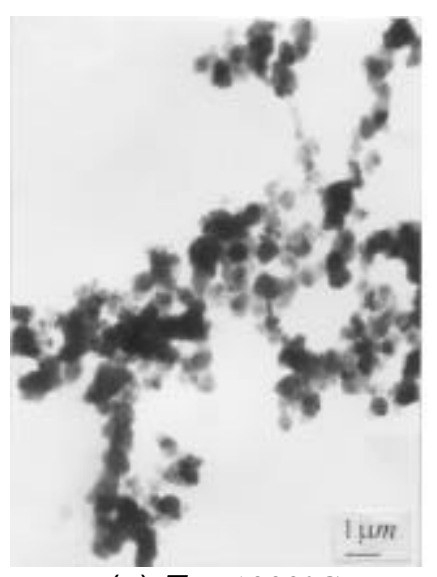

(a) $T_{\mathrm{c}}=1000^{\circ} \mathrm{C}$

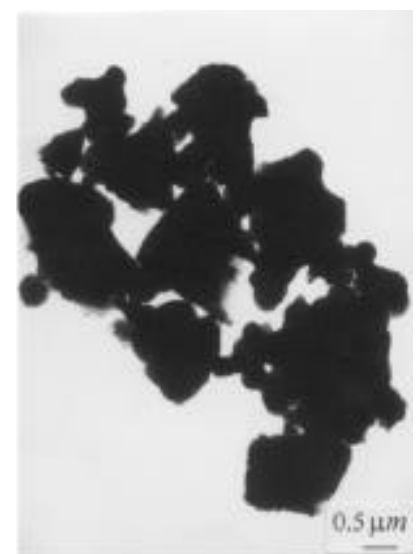

(b) $T_{\mathrm{c}}=1200^{\circ} \mathrm{C}$
Figure 6. TEM photographs of $\mathrm{Ni}-\mathrm{Zn}$ ferrite powder.

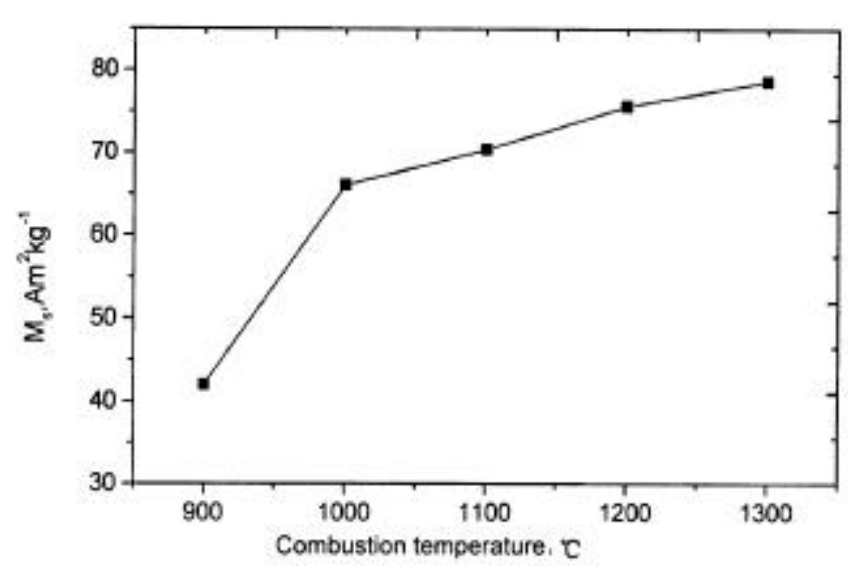

Figure 7. Maximum saturation magnetization, $M_{\mathrm{s}}$ vs combustion temperature.

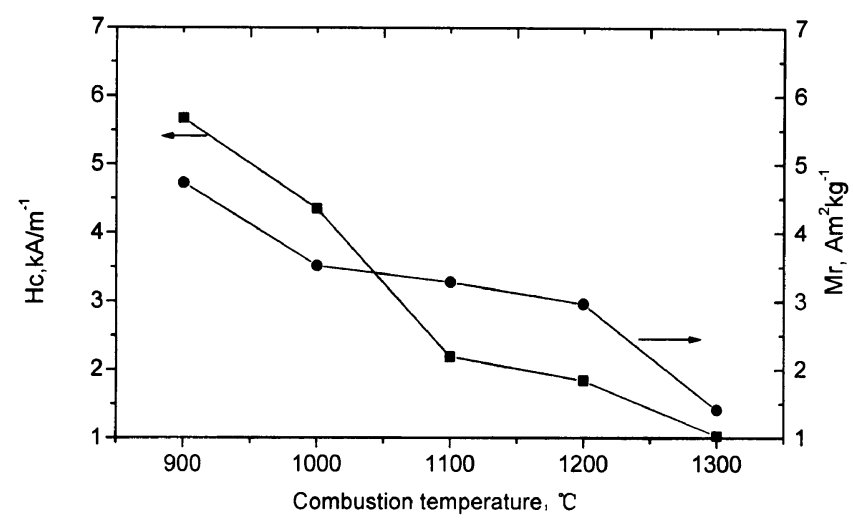

Figure 8. Coercivity force, $H_{\mathrm{c}}$ and residual magnetization, $M_{\mathrm{r}}$ vs combustion temperature.
Figure 4 shows the particle size distribution of $\mathrm{Ni}-\mathrm{Zn}$ ferrite powder obtained at $1000^{\circ} \mathrm{C}$. The average particle size of the powders is about $0.5 \mu \mathrm{m}$.

Figure 5 shows the XRD patterns of the combustion products obtained at different combustion temperatures. It is evident that as the combustion temperature increased from $700-1200^{\circ} \mathrm{C}$, the intensity of diffraction peaks of the raw materials, $\mathrm{NiO}, \mathrm{ZnO}, \mathrm{Fe}$ and $\mathrm{Fe}_{2} \mathrm{O}_{3}$ phases, decreased considerably, while the intensity of the combustion products increased. At $1000^{\circ} \mathrm{C}$, the diffraction peaks of $\mathrm{Fe}, \mathrm{NiO}, \mathrm{ZnO}$ disappeared and spinel peaks of ferrites were observed clearly in the X-ray spectra of the combustion products. At $1200^{\circ} \mathrm{C}$, the XRD can be indexed as a spinel-type phase with no additional lines corresponding to any other phase. However, the diffraction peaks are fairly sharp, due to the grain growth of the crystallites at higher combustion temperature.

The products prepared at different combustion temperatures are shown in figure 6. It clearly shows sphericalshaped particles with an average particle size of about $0.5 \mu \mathrm{m}$ at low combustion temperature $\left(1000^{\circ} \mathrm{C}\right)$ and with a tendency towards an anomalous shape for higher combustion temperature $\left(1200^{\circ} \mathrm{C}\right)$. The combustion products at $1200^{\circ} \mathrm{C}$ are too hard to be ground easily and such products cannot be used for sintering. At $1000^{\circ} \mathrm{C}$ the distribution of the particle grain size is homogeneous.

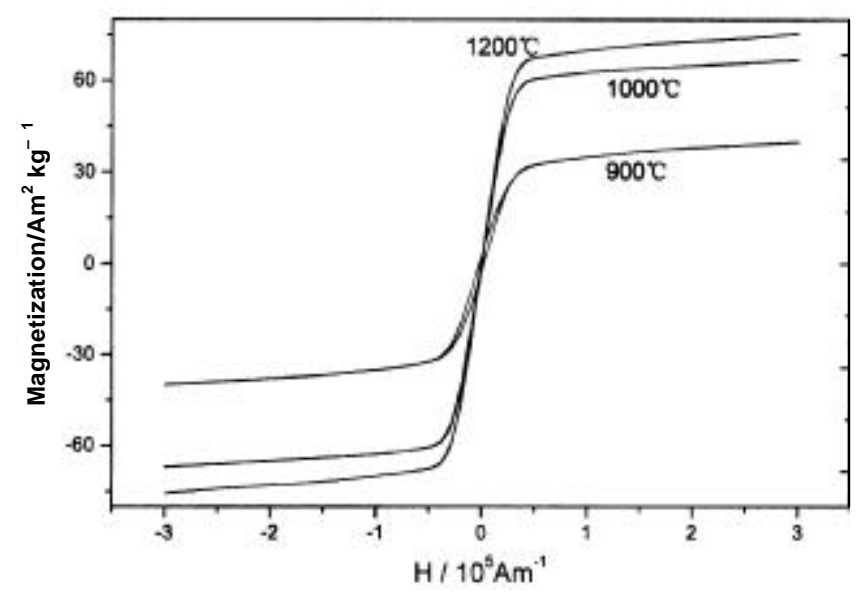

Figure 9. Hysteresis loops for SHS ferrite powders prepared at different combustion temperatures.

Table 2. Comparison between the $M_{\mathrm{s}}$ of $\mathrm{Ni}-\mathrm{Zn}$ ferrite powders obtained by SHS and other processing methods.

\begin{tabular}{llc}
\hline Reference & \multicolumn{1}{c}{ Synthesis methods } & $M_{\mathrm{s}}\left(\mathrm{A} \cdot \mathrm{m}^{2} \cdot \mathrm{kg}^{-1}\right)$ \\
\hline Present work & SHS & $66 \cdot 20$ \\
Anil Kumar (1997) & Wet chemical & $45 \cdot 5$ \\
Guo and Feng (1990) & Solid reaction & $48 \cdot 5$ \\
Hayashi et al (1986) & Molten salt synthesis & 65 \\
Jiang et al $(1999)$ & High energy ball milling & 66 \\
\hline
\end{tabular}


The room temperature magnetic properties of $\mathrm{Ni}_{0.35} \mathrm{Zn}_{0.65}$ $\mathrm{Fe}_{2} \mathrm{O}_{4}$ ferrite powders prepared under different combustion temperatures are determined. The results of the studies are summarized in figures 7 and 8 . The maximum saturation magnetization, $M_{\mathrm{s}}$, increases with combustion temperature indicating the growth of grain size and high degree of ferritization, while residual magnetization, $M_{\mathrm{r}}$, and coercive force, $H_{\mathrm{c}}$, decrease. Figure 9 shows the room temperature hysteresis loops of the combustion products obtained at different combustion temperatures.

The values of $M_{\mathrm{s}}$ are also compared with those of the literature. Table 2 shows the $M_{\mathrm{s}}$ of SHS products and other ferrite powders having similar compositions and obtained by different ceramic processing methods. We verified that the SHS process leads to nickel-zinc ferrite powders with improved magnetic properties, when compared with those obtained by other methods.

\section{Conclusions}

$\mathrm{Ni}_{0.35} \mathrm{Zn}_{0.65} \mathrm{Fe}_{2} \mathrm{O}_{4}$ ferrite powders were synthesized by SHS method. With the increase of combustion temperature, particle size of the powders increased. The results of $\mathrm{XRD}$ and TEM showed that at $1000^{\circ} \mathrm{C}$, the crystal structure of the combustion product was a spinel-type phase and the distribution of the particle size was homogeneous and with an average particle size of about $0.5 \mu \mathrm{m}$. Compared with other methods, $\mathrm{Ni}-\mathrm{Zn}$ ferrite powders with improved magnetic properties can be obtained by SHS method at $1000^{\circ} \mathrm{C}$.

\section{Acknowledgements}

The authors thank the Harbin Institute of Technology Foundation (Grant No. 2000.43) and the Heilongjiang Province Natural Science Foundation of China that supported this research.

\section{References}

Anil Kumar P S 1997 J. Appl. Phys. 814788

Avakyan P B, Mkrtchyan S O and Toroyan G L 1994 Int. J. SHS 3333

Bowen C R and Derby B 1997 Br. Ceram. Trans. 125

Guo B J and Feng Z K 1990 Magnetic films and powders (Cheng Du: University of Electric Science and Technology Press), p.173 (in Chinese)

Hayashi Y, Kimura T and Yamaguchi T 1986 J. Mater. Sci. 21 2876

Jiang J S, Gao L and Yang X L 1999 J. Mater. Sci. Lett. 18 1783

Komarov A V et al 1993 Int. J. SHS 2239

Stoppels D 1996 J. Magn. Magn. Mater. 160323

Taylor J A, Reczek S T and Rosen 1995 Am. Ceram. Soc. Bull. 7491 